\title{
How stable are mineral-organic associations? Contrasting exudate- mediated mobilization mechanisms in the rhizosphere
}

MARCo KeILUWEIT ${ }^{1}$, HUI Li ${ }^{1}$, MATTHEW WINNICK ${ }^{1}$, MALAK TFAILY $^{2}$, AND ZOE G. CARDON ${ }^{3}$

${ }^{1}$ University of Massachussets Amherst (keiluweit@umass.edu)

${ }^{2}$ University of Arizona

${ }^{3}$ Marine Biology Laboratory

Soil is the largest carbon (C) reservoir in terrestrial environments. Most of that $\mathrm{C}$ is stored in mineral-organic associations (MOAs), where it is protected against microbial mineralization. Recent evidence suggests that the stability of MOAs can be undermined by rhizosphere processes induced by plant or microbial exudates. However, the mechanisms by which exudates disrupt different types of mineral-organic associations are unclear. Here we tested the ability of functionally distinct model exudates - ligands, reductants, and simple sugars - to facilitate mobilization and mineralization of ${ }^{13} \mathrm{C}$-labeled organic matter associated with common $\mathrm{Fe}$ and $\mathrm{Al}$ (hydr)oxide minerals of varying crystallinity. All model exudates enhanced mobilization and mineralization of mineralassociated C. Rapid, ligand-induced mobilization of mineralassociated $\mathrm{C}$ coincided with greater sorption to and dissolution of minerals, suggesting that direct mechanisms such as surface displacement or dissolution dominate. In contrast, simple sugars caused slower mobilization of mineral-associated $\mathrm{C}$, coinciding with increased microbial respiration, protein abundance, and metabolite production, indicating that indirect, microbially-mediated mechanisms are responsible. Organic reductants, acting both as a ligand and $\mathrm{C}$ source for microbes, promoted both direct and indirect mechanisms. We further found that $\mathrm{C}$ bound to poorly crystalline (hydr)oxides is more vulnerable to exudate-induced destabilization than $\mathrm{C}$ bound to more crystalline phases, particularly in response to direct, ligand-promoted mechanisms. Our results demonstrate that the stability of MOAs is not just a function of their inherent properties, but also will depend in large parts on the ability of plant roots and microbes to produce exudates capable of triggering suitable mobilization mechanisms. 